\title{
Access to Treatment for Drug Use Disorders at US Health Centers: a National Study
}

\author{
Benjamin Bearnot, $M D^{1,2}$, Danielle R. Fine, $M D^{1,2}$, Nancy A. Rigotti, $M D^{1,2,3}$, and \\ Travis P. Baggett, MD, MPH ${ }^{1,2,4}$
}

'Division of General Internal Medicine, Department of Medicine, Massachusetts General Hospital, Boston, MA, USA; ${ }^{2}$ Department of Medicine, Harvard Medical School, Boston, MA, USA; ${ }^{3}$ Tobacco Research and Treatment Center, Division of General Internal Medicine, Department of Medicine, Massachusetts General Hospital, Boston, MA, USA; ${ }^{4}$ nstitute for Research, Quality, and Policy in Homeless Health Care, Boston Health Care for the Homeless Program, Boston, MA, USA.

$\mathrm{J}$ Gen Intern Med 34(12):2723-5

DOI: $10.1007 / \mathrm{s} 11606-019-05043-1$

(c) Society of General Internal Medicine 2019

\section{INTRODUCTION}

Drug use disorders (DUDs) and associated overdose deaths are a growing public health concern in the USA, contributing to the first decrease in American life expectancy in over 100 years. ${ }^{1}$ Treatment for drug addiction remains uncommon despite the availability of evidence-based behavioral and pharmacologic treatments for many substances. We previously described the need for and barriers to alcohol use disorder care at federally funded US health centers, ${ }^{2}$ which provided safetynet care to more than 27 million Americans in 2017, but access to DUD care in this population remains underexplored. The objective of the current study was to examine the continuum of DUD care, location of treatment delivery, and barriers to receiving drug use treatment among health center attendees with symptoms of DUD.

\section{METHODS}

We analyzed data from adult ( $\geq 18$ years old) respondents to the 2014 Health Center Patient Survey. This was a nationally representative, cross-sectional, in-person survey of Health Resources and Services Administration (HRSA) health center attendees conducted between September 2014 and April 2015 using a three-stage sampling design. ${ }^{3}$ We defined current

Prior Presentations American Society of Addiction Medicine, 2019 National Conference in Orlando, FL; Society of General Internal Medicine, 2019 National Conference in Washington D.C.

Received April 11, 2019

Accepted April 16, 2019

Published online May 14, 2019
DUD based on responses to the World Health Organization Alcohol, Smoking and Substance Involvement Screening Test questionnaire, ${ }^{4}$ which includes items that assess past 3-month symptoms corresponding to 5 of 11 Diagnostic and Statistical Manual of Mental Disorders criteria for cannabis, cocaine, amphetamine-type stimulants, sedatives, inhalants, hallucinogens, and opioid use disorders. Individuals who endorsed $\geq 2$ current symptoms for any substance were defined as having a diagnosis of DUD. We examined responses to a series of questions regarding receipt of DUD-related counseling and care, the location of this care, and the primary reason individuals were unable to access treatment. We examined whether these measures differed between health center subtypes where DUD was most common, Community Health Centers (CHC) and Health Care for the Homeless $(\mathrm{HCH})$ programs. We conducted analyses in SAS (SAS Institute) v9.4, using strata, cluster, and weight variables to account for the complex sampling design and produce estimates representative of US health center attendees. Rao-Scott $\chi^{2}$ tests were used to compare proportions, with a two-sided $p$ value $<0.05$ for significance. The Partners Human Research Committee exempted this study.

\section{RESULTS}

Among 5547 adult patients, 374 (4.5\%) had current evidence of DUD. The most common DUDs were cannabis (63.0\%), sedative $(16.8 \%)$, stimulant $(14.1 \%)$, cocaine $(13.7 \%)$, and opioid use disorder (7.7\%). Two hundred ninety-three individuals $(85.3 \%)$ had a single DUD, while $81(14.7 \%)$ had DUDs involving two or more substances, most often cannabis $(N=$ 49). Table 1 summarizes drug use disorders, demographic characteristics including clinic type, and health status differences between those with and without DUD.

Half $(49.7 \%)$ of those with a DUD reported discussing drug use with a health professional, $35.7 \%$ reported wanting 
Table 1 Characteristics of Patients With and Without Current Evidence of Drug Use Disorder at US Community Health Centers

\begin{tabular}{|c|c|c|c|c|c|}
\hline & \multicolumn{2}{|c|}{ Drug user disorder } & \multicolumn{2}{|c|}{ No drug use disorder } & \\
\hline & \multicolumn{2}{|l|}{$N=374(4.5 \%)$} & \multicolumn{2}{|l|}{$N=5173(95.5 \%)$} & \\
\hline Drug use disorder* & Unweighted no. & Weighted \% & Unweighted no. & Weighted \% & \\
\hline Cannabis & 2177 & 63.0 & - & - & \\
\hline Sedatives & 50 & 16.8 & - & - & \\
\hline Stimulants & 75 & 14.1 & - & - & \\
\hline Cocaine & 85 & 13.7 & - & - & \\
\hline Opioids & 52 & 7.7 & - & - & \\
\hline Inhalants/hallucinogens & $<30$ & 1.9 & - & - & \\
\hline Demographics & Unweighted no. & Weighted \% & Unweighted no. & Weighted \% & $p$ value \\
\hline \multicolumn{6}{|l|}{ Age } \\
\hline $18-44$ & 182 & 70.2 & 2071 & 51.3 & \multirow[t]{3}{*}{0.002} \\
\hline $45-64$ & 185 & 28.1 & 2557 & 37.0 & \\
\hline$\geq 65$ & $<30$ & 1.7 & 545 & 11.6 & \\
\hline Women & 160 & 61.7 & 3330 & 64.3 & 0.70 \\
\hline \multicolumn{6}{|l|}{ Race/ethnicity } \\
\hline Non-Hispanic white & 104 & 43.2 & 1258 & 51.0 & \multirow[t]{5}{*}{0.09} \\
\hline Non-Hispanic black & 150 & 31.5 & 1143 & 18.8 & \\
\hline Non-Hispanic Asian & $<30$ & 0.6 & 341 & 3.2 & \\
\hline Non-Hispanic other & 49 & 6.2 & 610 & 2.9 & \\
\hline Hispanic & 65 & 18.6 & 1819 & 24.2 & \\
\hline Urban location & 296 & 60.9 & 3607 & 47.1 & 0.12 \\
\hline High school diploma & 218 & 59.0 & 2891 & 66.3 & 0.31 \\
\hline Currently employed & 73 & 32.4 & 1698 & 37.5 & 0.43 \\
\hline \multicolumn{6}{|l|}{ Federal poverty level (\%) } \\
\hline$\leq 100$ & 297 & 71. & 3303 & 55.1 & \multirow[t]{3}{*}{0.07} \\
\hline$\overline{1} 101-199$ & 51 & 17.9 & 1362 & 29.5 & \\
\hline$\geq 200$ & $<30$ & 10.3 & 506 & 15.4 & \\
\hline \multicolumn{6}{|l|}{ Health insurance } \\
\hline None & 62 & 23.3 & 1299 & 27.0 & \multirow[t]{3}{*}{0.03} \\
\hline Public & 283 & 69.6 & 3119 & 53.0 & \\
\hline Private & $<30$ & 7.2 & 755 & 20.0 & \\
\hline \multicolumn{6}{|l|}{ Health center type } \\
\hline Community Health Center & 119 & 83.1 & 3026 & 93.2 & \multirow[t]{4}{*}{$<0.001$} \\
\hline Health for the Homeless & 201 & 14.1 & 960 & 2.8 & \\
\hline Public Housing Primary Care & 40 & 1.8 & 407 & 0.9 & \\
\hline Migrant Health Care & $<30$ & 1.0 & 780 & 3.1 & \\
\hline Health status & Unweighted no. & Weighted \% & Unweighted no. & Weighted \% & $\mathrm{P}$ value \\
\hline Fair or poor health & 187 & 49.6 & 2557 & 42.1 & 0.24 \\
\hline Fair or poor oral health & 186 & 51.3 & 1964 & 42.7 & 0.23 \\
\hline Severe psychological distress ${ }^{\dagger}$ & 136 & 36.1 & 768 & 13.7 & 0.002 \\
\hline
\end{tabular}

Cell sizes $<30$ have been suppressed to protect participant confidentiality. Weighted \% are representative of all health center attendees *Eighty-one participants reported more than 1 DUD; 58 with 2 DUDs; and 23 with $>2$ DUDs

† Score $\geq 13$ on the Kessler 6-item scale of psychological distress

or needing treatment, and $28.3 \%$ reported receiving treatment for DUD in the past year (Fig. 1). There were no significant differences between $\mathrm{CHC}$ and $\mathrm{HCH}$ attendees in reporting past-year discussion of drug use with a health care provider ( $49 \%$ vs. $55 \%, p=0.54)$, wanting or needing DUD treatment ( $33 \%$ vs. $53 \%, p=0.15)$, or receiving DUD treatment ( $26 \%$ vs. $45 \%, p=0.16)$.

Of 102 individuals who reported receiving past-year DUD treatment, $63 \%$ did so outside of a HRSA health center. Among 41 respondents who wanted but did not receive DUD treatment, the most commonly reported reasons for not obtaining treatment were stigma (69\%), skepticism about treatment (14\%), and logistical (12\%) and financial barriers $(5 \%)$.

\section{DISCUSSION}

DUDs were common in this representative study of health center attendees, providing estimates in line with other national samples. ${ }^{5}$ Cannabis use disorder was the most frequent DUD and often co-occurred with other substance use disorders. Only half of those with DUD discussed their drug use with a health professional, and fewer still reported wanting or receiving treatment for their drug use. Nearly two-thirds of individuals who received addiction treatment obtained it outside of their health center.

Limitations of this study include self-reported data about stigmatized conditions, an incomplete measure of DUD prevalence, and small sample sizes for some aspects of the analysis, limiting generalizability. While rising synthetic opioid and polysubstance drug use have contributed to drug overdose 


\section{Continuum of Drug Use Disorder Care}

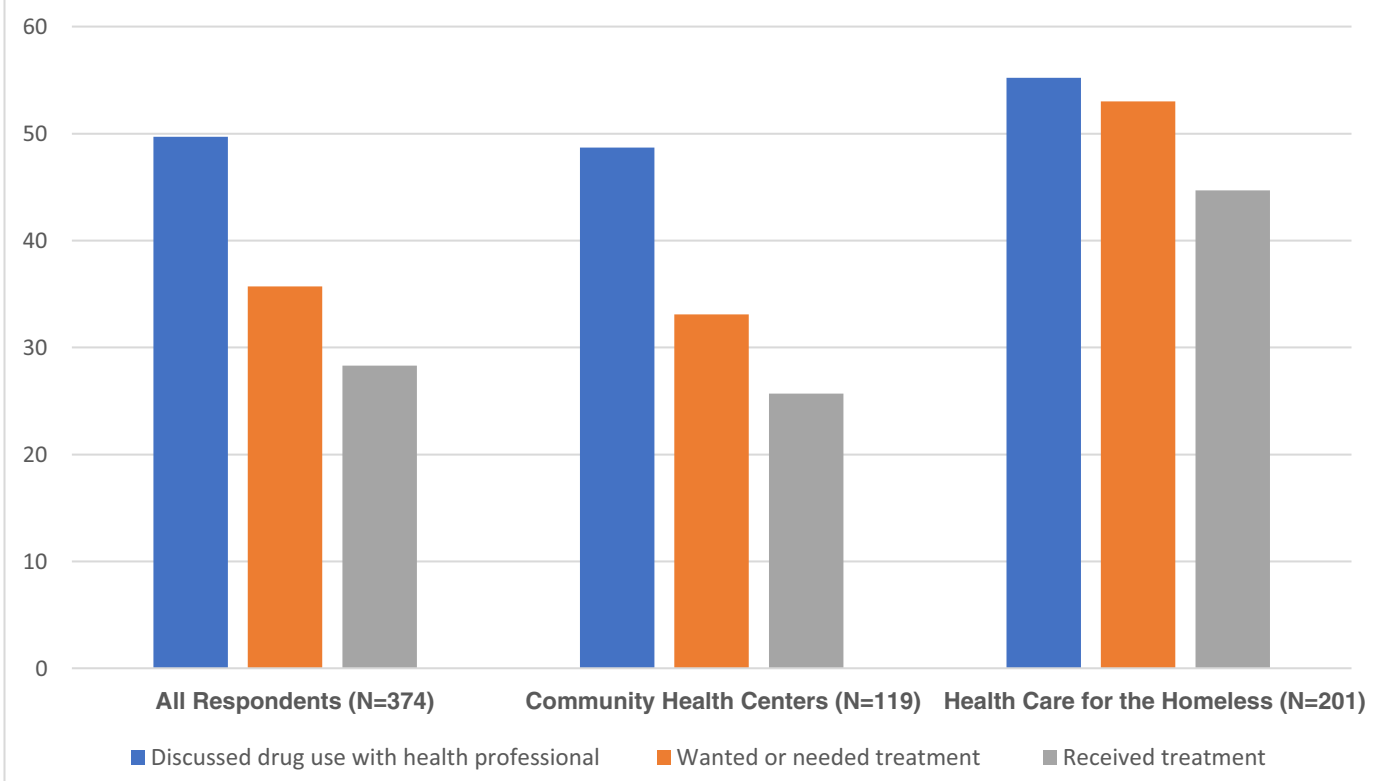

Figure 1 Continuum of DUD care among health center attendees. Differences between Community Health Center and Health Care for the Homeless respondents are not statistically significant for any of the measures presented.

deaths nationally, ${ }^{6}$ drop-offs in engagement across the continuum of DUD care in this study highlight multiple addressable barriers to identifying individuals with substance use disorders and consistently linking them to effective addiction treatment from safety-net health centers.

Corresponding Author: Benjamin Bearnot, MD; Division of General Internal Medicine, Department of Medicine, Massachusetts General Hospital, Boston, MA, USA (e-mail: bbearnot@partners.org).

Funders Dr. Baggett is financially supported by the Massachusetts General Hospital Department of Medicine Transformative Scholars Program.

Data Availability While some elements of HCPS are available publicly, we requested permission from HRSA to analyze a restricted use file which included information regarding participants' drug use behaviors. The public use files are available from HRSA repository: https:// bphc.hrsa.gov/datareporting/research/hcpsurvey/index.html

\section{Compliance with Ethical Standards:}

The Partners Human Research Committee found this study to be exempt

Conflict of Interest: Benjamin Bearnot has no conflicts to report. Danielle Fine has no conflicts to report. Travis Baggett receives royalties from UpToDate for authorship of a topic review on homeless health care. Nancy Rigotti receives royalties from UpToDate for reviews of tobacco cessation topics and consults with Achieve Life Sciences regarding tobacco cessation and received a research grant and been as an unpaid consultant to Pfizer regarding tobacco cessation.
Disclaimer: The funding agency had no role in any aspect of this study.

Prior Presentations: American Society of Addiction Medicine, 2019 National Conference in Orlando, FL; Society of General Internal Medicine, 2019 National Conference in Washington D.C.

\section{REFERENCES}

1. Murphy SL, Xu JQ, Kochanek KD, Arias E. Mortality in the United States, 2017. NCHS Data Brief, Number 328. Hyattsville, MD: National Center for Health Statistics; 2018. https://www.cdc.gov/nchs/products/ databriefs/db328.htm. Accessed March 18, 2019.

2. Bearnot B, Rigotti N, Baggett TP. Access to treatment for alcohol use disorder at U.S. health centers: a national study. J Gen Int Med. 2018; 33(12): 2040-2042.

3. Health Resources and Services Administration. Health Center Patient Survey. https://bphc.hrsa.gov/datareporting/research/hcpsurvey/index. html. Accessed March 5, 2019.

4. World Health Organization. The ASSIST project - Alcohol, Smoking and Substance Involvement Screening Test. http://www.who.int/substance abuse/activities/assist/en/. Accessed March 5, 2019.

5. Substance Abuse and Mental Health Services Administration. Key substance use and mental health indicators in the United States: Results from the 2017 National Survey on Drug Use and Health. Rockville, MD: Center for Behavioral Health Statistics and Quality, Substance Abuse and Mental Health Services Administration; 2018. https://www.samhsa.gov/data/. Accessed March 18, 2019.

6. Jones CM, Einstein EB, Compton WM. Changes in synthetic opioid involvement in drug overdose deaths in the United States, 2010-2016. JAMA. 2018; 319(17):1819-1821.

Publisher's Note Springer Nature remains neutral with regard to jurisdictional claims in published maps and institutional affiliations. 